\title{
Image J Analysis of Six Different Annealed Temperatures of $0.17 \%$ C of HSLA Steels
}

\author{
Ngozi Grace Emordi1 ${ }^{1}$ Iweriolor Sunday², Onyekpe Basil Obimma ${ }^{3}$ \\ ${ }^{1}$ Department of Metallurgical Engineering, Delta State Polytechnic, Ogwashi Uku, Nigeria \\ ${ }^{2}$ Department of Mechanical Engineering, Delta State Polytechnic, Ogwashi Uku, Nigeria \\ ${ }^{3}$ Department of Mechanical Engineering, University of Benin, Benin, Nigeria \\ Email: sundaytrevor1234@gmail.com
}

How to cite this paper: Emordi, N.G. Sunday, I. and Obimma, O.B. (2020) Image J Analysis of Six Different Annealed Temperatures of $0.17 \% \mathrm{C}$ of HSLA Steels. World Journal of Engineering and Technology, 8, 617-629.

https://doi.org/10.4236/wjet.2020.84043

Received: August 14, 2020

Accepted: October 13, 2020

Published: October 16, 2020

Copyright (C) 2020 by author(s) and Scientific Research Publishing Inc. This work is licensed under the Creative Commons Attribution International License (CC BY 4.0).

http://creativecommons.org/licenses/by/4.0/

\section{Open Access}

\begin{abstract}
Annealing is a heat treatment procedure in which the mechanical properties of a material are being altered, and such alterations cause changes in its properties such as strength and hardness. It is usually carried out to improve ductility and toughness, to reduce hardness and to remove carbides. This study deals with the use of image analysis processing method for the measurement of structure of six annealed samples of $0.17 \%$ High Strength Low Alloy (HSLA) Steels $\left(840^{\circ} \mathrm{C}-990^{\circ} \mathrm{C}\right)$ with $30^{\circ} \mathrm{C}$ interval and 30 minutes soaking time. From the optical microscope images using Image J program, some parameters like calculation of area, pixel value statistics, distances and angles measurements, edge detection, such as the circularity, ferret angle, solidity and perimeter, average area and the percentage area were examined. The annealed sample of $960^{\circ} \mathrm{C}$ gave the highest grain count of 543 with a perimeter of 41.518; standard deviation 7.057 and a mean of 28.722 which shows that annealing greatly improved the fatigue life of the steel. From the mechanical analysis result, the annealed sample at $840^{\circ} \mathrm{C}$ has a highest hardness value of $129.4 \mathrm{BHN}$ and gave the lowest impact value of $58.75 \mathrm{~J}$. This study shows a significant decrease in the hardness value as the annealing temperature increased which signifies that annealing temperature enhanced the fatigue property and tensile strength (wear strength) of the steel in study.
\end{abstract}

\section{Keywords}

High Strength Low Alloy Steel, Microstructure, Image J

\section{Introduction}

An important feature of any Engineering component is its fatigue life and it's measured by the number of cycles it can withstand before Fatigue failure takes 
place. Fatigue is a problem that can affect any type of component that moves [1]. Heat treatment is an operation or combination of operations which involve heating at a specific rate. The aim is to obtain a desired microstructure to achieve certain predetermined properties (mechanical, physical, electrical or magnetic). Heat treatment and alloying are two methods which are considerably used for controlling material properties. In heat treatment, the microstructures of the materials are altered, which influences mechanical properties such as strength, ductility, toughness, hardness and wear [1]. Annealing in metallurgy and materials science is a heat treatment that alters the physical and sometimes the chemical properties of a material to increase its ductility and reduce its hardness, making it more workable. It involves heating the material to above its recrystallization temperature, maintaining a suitable temperature, and then cooling. [2] and [3] described annealing process as a thermal system applied to a material to transform or modify its internal structure from cold worked propagation; metallurgically, the effect of these changes in properties impacts on the performance characteristics and the expected application [4]. Annealing is the type of heat treatment most frequently applied in order to soften iron or steel materials and refines its grain due to ferrite-pearlite microstructure; it is used where elongations and appreciable level of tensile strength are required in engineering materials. [5] described annealing as a heat treatment procedure in which a material composition is altered, and such alterations cause changes in its properties such as strength and hardness. In this process, a material is heated to an elevated temperature for a specific period of time and then slowly cooled in the furnace. This kind of process is usually carried out to relieve stresses and improve ductility. It often enables the design of desired microstructure by altering the annealing parameters, such as annealing temperature and soaking time.

New materials that impart excellent structural performance; while reducing weight and being cost-effectively manufactured is on the increasing demand [6]. Due to this fact, for the past 30 years now, an exceptional type of steel which has low amount of carbon $(0.05-0.25)$ and also combines with other alloying elements like $\mathrm{Cr}, \mathrm{Ni}, \mathrm{Mo}, \mathrm{Cu}, \mathrm{N}, \mathrm{V}, \mathrm{Nb}, \mathrm{Ti}, \mathrm{W}$, and $\mathrm{Zr}$, in little proportions and in diverse concentrations has evolved often known as high strength low alloy HSLA steels. Manricino, in his work on fatigue failure analysis of High Strength Low Alloy steel sheet described High strength low alloy steels (HSLA) as steels that are made up of microstructures formed by hard martensite particles distributed in the ductile ferrite matrix [7]. They are compared to dual-phase steels due to their high hardening ability during deformation, high malleability and good surface quality [8]. It also contributes to the stiffness and weight reduction being preferred in automobile industry. This is attributed to its good formability characteristics. These groups of steels play an effective role in the production of parts in vehicles such as suspension systems, support elements, longitudinal beams, transverse components and chassis [9]. When these materials are exposed to high temperatures, there is a recrystallization of the microstructure in 
the heat affected zone which directly influences the resistance limit of the material [10] Utilization of HSLA steels are found in many engineering fields which include oil and gas pipelines, constructions and farm machinery, heavy-duty highway and off road vehicles, industrial equipment storage tanks, mine and rail road car, barges and dredges snow mobiles, power transmission towers light poles, lawn mowers, and passengers car components. Bridges, offshore structures, and building beams and panels are additional uses of these steels [11].

Image analysis deals generally with acquisition of quantitative information about various parameters of microstructure of a material such as determination of percentage fraction of phases, particular size, circularity etc. Circularity can be calculated as a shape parameter index in the Image J software. The definition of circularity (C I) in the Image J software is as follows:

$$
C_{1}=4 \pi \frac{A^{1}}{P_{1}^{2}}
$$

where, $A^{1}$ and $P_{1}$ are the area and the perimeter using Image J.

There are numerous commercial software such as Amira, Comsol multiphysics, etc., for analysis features [12]. However, this paper describes an investigation of six different annealed samples from $840^{\circ} \mathrm{C}-990^{\circ} \mathrm{C}$ with $30{ }^{\circ} \mathrm{C}$ interval of $0.17 \%$ C HSLA steels structure analyzing from OM image using Image J program software [13]. Several researchers have investigated DP steels to find out the effect of heat treatment, soaking times on its properties. Miroslaw, $2020 \mathrm{ob}-$ served that annealing process reduces the true stress and effectively decreases the hardness of $42 \mathrm{CrMO}_{4}$ Steel and also improves microstructural Spherodization [14]. Senthil reported that improved fatigue strength was attainable by the combined heat treatment process of Nitriding followed by induction hardening [15]. The quantitative measurement of the influence of Annealing on the fatigue life of SAE202 and $440^{\circ} \mathrm{C}$ steels from his results, he concluded that there is a definite improvement in the fatigue life due to annealing in both steels; however, the extent of improvement was more in $440^{\circ} \mathrm{C}$ steel when compared to SAE202. Gaurav, 2018 reported that to improve fatigue life, effect of heat treatment on fatigue life and strength need to be studied for better designing and mechanical system. Also, little or no work has been done to set out the fatigue life of HSLA steel at different annealing temperature; hence this work investigated on the use of Image $J$ to analyze the effect of annealing temperatures on the fatigue properties of $0.17 \%$ C HSLA steels.

\section{Materials and Method}

Samples of HSLA steel containing about $0.17 \%$ Carbon were provided and used for this experiment. The samples were grouped into 10 having 5 samples in each of the group. They were then heat treated at different pre-determined temperature as follows: $840^{\circ} \mathrm{C}, 870^{\circ} \mathrm{C}, 900^{\circ} \mathrm{C}, 930^{\circ} \mathrm{C}, 960^{\circ} \mathrm{C}$ and $990^{\circ} \mathrm{C}$ respectively and the control which served as the austenizing temperature. Furthermore each of these group of five were held at 30 minutes interval and were then left to cool in 
the furnace (annealing) before various test were carried out on them..

\subsection{Heat Treatment}

This section is aimed at producing microstructures from the as-received steel through different annealing temperatures. The focus here is to develop different microstructure at different temperatures for each of the samples, with a view to determining the effect of the new microstructures on the mechanical properties of the investigated steel.

\subsection{Normalizing}

This was done to remove the effect of past mechanical, thermo-mechanical or thermal treatment the steel has been subjected to. This was done by heating the sample to $890^{\circ} \mathrm{C}$, soaking for one hour $(1 \mathrm{hr}$ ) in the furnace (muffle) and then allowing it to cool in air.

\subsection{Annealing}

Before the annealing was done the Carbon equivalent was calculated to tell the starting temperature from the Iron Carbon phase diagram.

$$
\mathrm{CE}=\mathrm{C}+\frac{\mathrm{Cr}+\mathrm{Mo}+\mathrm{V}}{5}+\frac{\mathrm{Mn}+\mathrm{Si}}{6}+\frac{\mathrm{Ni}+\mathrm{Cu}}{15}
$$

From the chemical composition, we have

$$
\mathrm{Cr}=0.2559 ; \mathrm{Mo}=0.0100 ; \mathrm{V}=0.0100 ; \mathrm{Mn}=1.2089 ; \mathrm{Si}=0.3016 \mathrm{Ni}=0.1218
$$

and $\mathrm{Cu}=0.2560$ and $\mathrm{C}=0.17$

Substituting these figures in Equation 2 above, we have

$$
\begin{gathered}
\mathrm{CE}=0.17+\frac{0.2559+0.0100+0.0100}{5}+\frac{1.2089+0.3016}{6}+\frac{0.1218+0.2560}{15} \\
\mathrm{CE}=0.17+0.05518+0.25175+0.02513=0.50206 \text { hence } \mathrm{CE} \text { is } 0.5
\end{gathered}
$$

\subsection{Metallographic Examination}

\subsubsection{Grinding}

This operation aims at producing a perfectly flat and smooth surface Silicon carbide papers of different grades placed on the grinding machine was used in the order of 220,320, 400 and 600 grits paper i.e. from coarse grade to finer grade. The grinding process was done under running water to wash away the grits and also to avoid overheating. The samples were turned through $90^{\circ}$ while changing from one grit size to another in the materials laboratory at Obafemi Awolowo University, Ile-Ife. Osun state, Nigeria.

\subsubsection{Polishing}

A universal polishing machine was employed. A polishing cloth (selvt cloth) was placed on the polisher for the initial polishing swamped with solution of one micron of silicon carbide solution, then, followed by the final polishing stage with salvet cloth swamped with solution of $0.5 \mu \mathrm{m}$ Silicon carbide until a mirror-like surface is attainable. It is then washed and dried. 


\subsubsection{Etching}

This is done to reveal the microstructure of the polished surface. Etching is the selective attack on the grain boundaries being a region of high energy and dislocation density. The mirror-like surface was etched in $2 \%$ NITAL. The sample was again washed, dried and later viewed under the metallurgical microscope.

\subsubsection{Optical Microscopy}

The samples were etched in 2\% NITAL (2\% Nitric Acid and 98\% Ethyl Alcohol), they were put in a desiccator and viewed with metallurgical optical microscope.

\section{Results and Discussion}

Figure 1 showed the flowchart of the Image J process of HSLA Steel. In Figure 2(a) Steels taken with metallurgical Optical microscope. The images were uploaded and analyzed with image J software after the capturing of the micrographs. The Image J analysis was then used to analyze for the following parameters, standard deviation, perimeter, angle, circularity, percentage area, ferret angle, roundness, solidity, histogram, 3D dimensioned and results are presented in plate 1:0. Images in Figure 2(a) were threshold by using Image-Adjust and Threshold tool. The threshold color images of Figure 2(b) were masked to give the outlines in Figure 2(d) while Figure 2(f) showed the 3D interactive surface plot drawn by intensity of any color offers a basic vision of observed surface morphology of the steel such as the grid size, the smoothing and the perspective of the minimum and maximum percentage in relation to the z-scale. The circularity (shape descriptors) parameter allows for evaluating the shape of grains. Figure 2(e) showed the bins which is the number used for the particle size distribution histogram while Table 1 showed the microstructural parameters of the six annealed samples of HSLA steels using the Image J analysis (Figures 2-7).

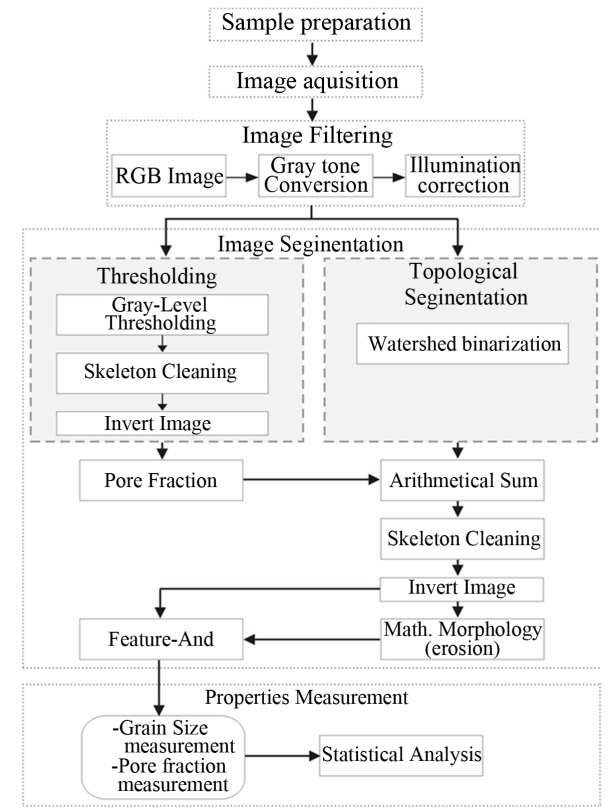

Figure 1. Flowchart of the image J process of $0.17 \%$ Of HSLA steel. 


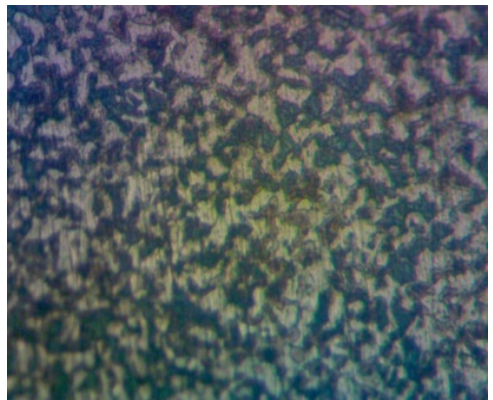

(a)

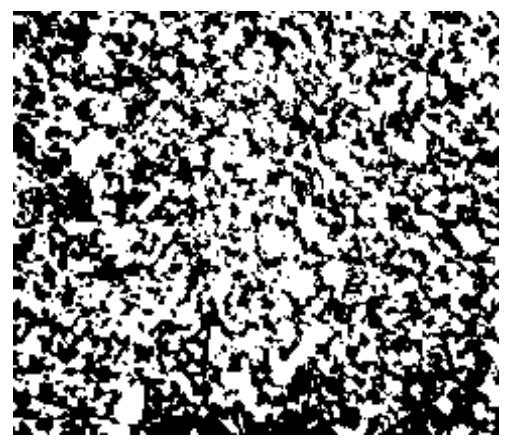

(c)

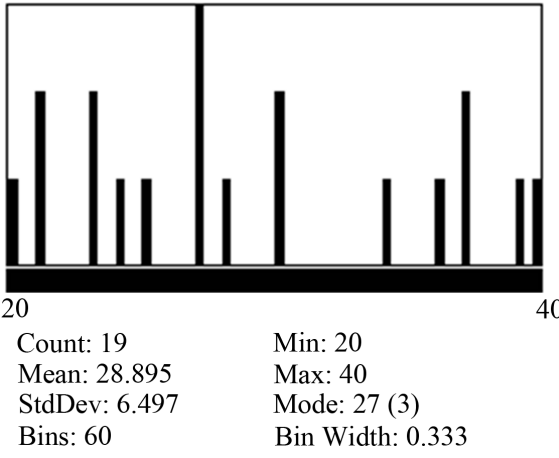

(e)

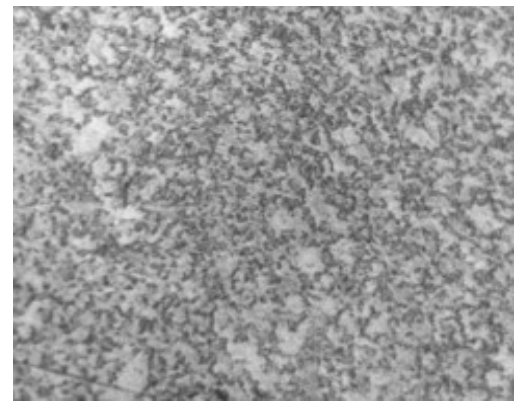

(b)

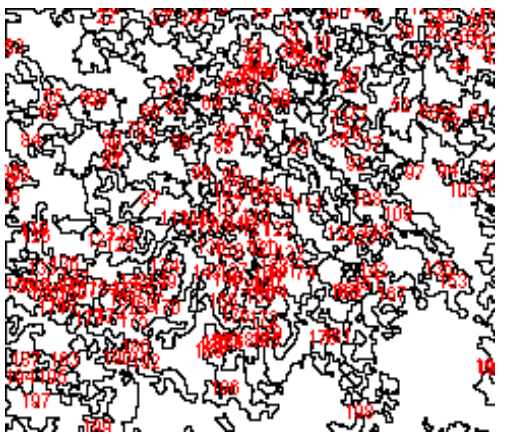

(d)

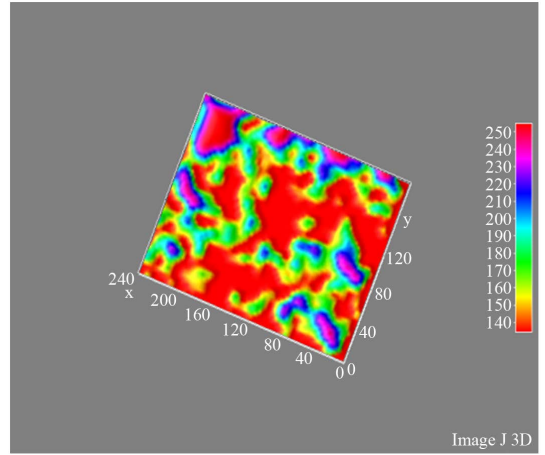

(f)

Figure 2. Processed image of $840^{\circ} \mathrm{C}$ annealed steel by image analysis (using) Image J. (a) Original image - Optical Microscope (b) processing and threshold (blue); (c) thresholded (black and white) (d) result of particle distribution (using analysis tool in Image J) (e) Area distribution of the grains (f) Interactive 3D surface plot.

Table 1. Microstructural properties of six annealed samples of $0.17 \%$ HSLA steels by image J analysis.

\begin{tabular}{cccccccccccccc}
\hline $\begin{array}{c}\text { TEMP } \\
{ }^{\circ} \mathrm{C}\end{array}$ & COUNT & $\begin{array}{c}\text { TOTAL } \\
\text { AREA }\end{array}$ & $\begin{array}{c}\text { AV. } \\
\text { SIZE }\end{array}$ & $\begin{array}{c}\% \\
\text { AREA }\end{array}$ & CIRC perimeter FERET & $\begin{array}{c}\text { FER } \\
\text { RET X }\end{array}$ & $\begin{array}{c}\text { FERET } \\
\text { Y }\end{array}$ & $\begin{array}{c}\text { FERET } \\
\text { ANG }\end{array}$ & $\begin{array}{c}\text { MINI } \\
\text { FERET }\end{array}$ \\
\hline 840 & 199 & 22384 & 112.482 & 47.63 & 0.176 & 59.041 & 9.823 & 113.236 & 811.724 & 119.645 & 5.983 \\
870 & 332 & 26309 & 79.244 & 41.45 & 0.359 & 36.901 & 9.801 & 127.145 & 105.611 & 108.258 & 5.248 \\
900 & 182 & 29195 & 160.412 & 49.45 & 0.419 & 50.976 & 10.154 & 135.709 & 86.714 & 116.23 & 6.148 \\
930 & 383 & 19038 & 49.708 & 41.49 & 0.149 & 30.169 & 7.439 & 131.164 & 78.324 & 111.266 & 4.108 \\
960 & 543 & 51205 & 94.300 & 46.88 & 0.334 & 41.518 & 7.793 & 203.157 & 114.245 & 108.275 & 4.576 \\
990 & 290 & 29802 & 102.766 & 50.68 & 0.224 & 42.166 & 7.534 & 164.414 & 91.910 & 111.731 & 4.305 \\
\hline
\end{tabular}




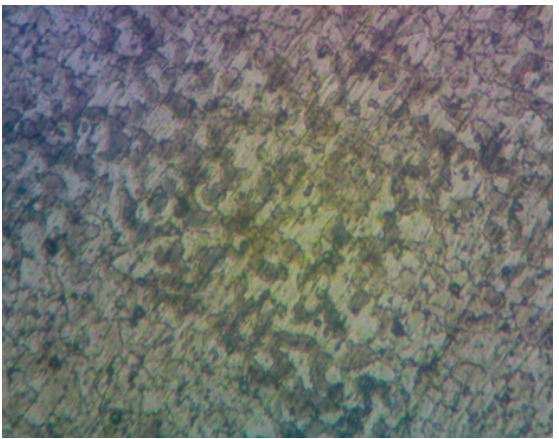

(a)

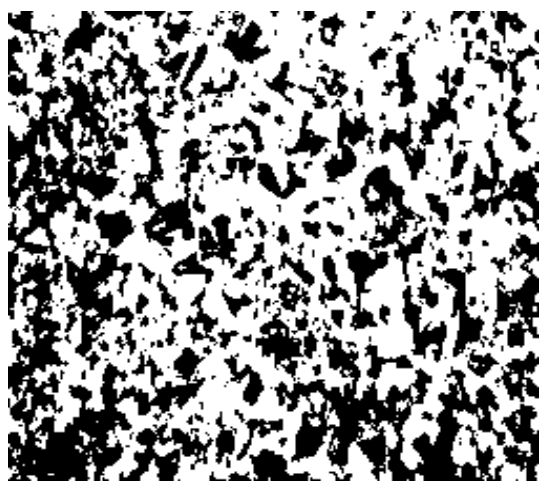

(c)

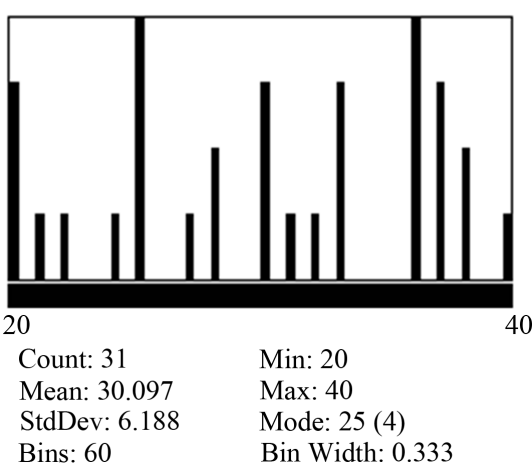

(e)

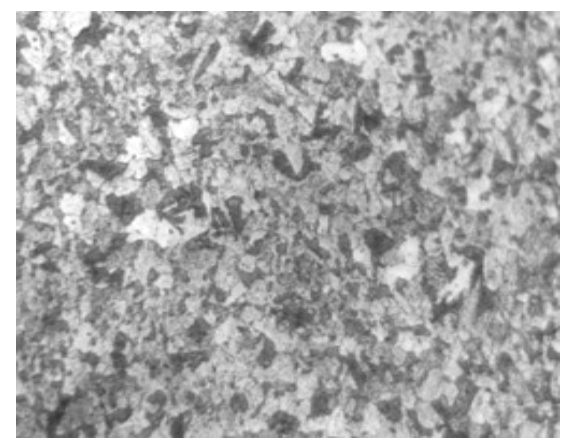

(b)

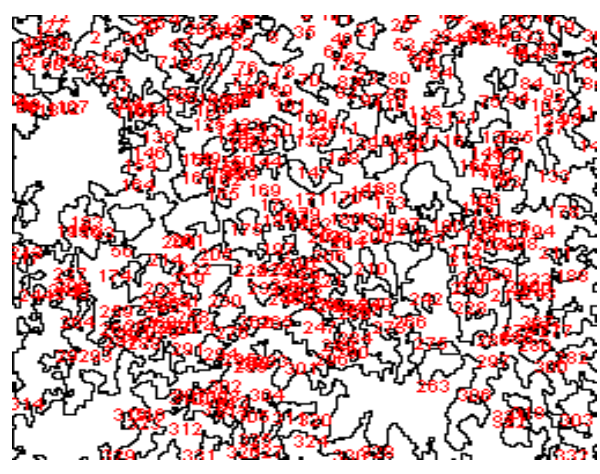

(d)

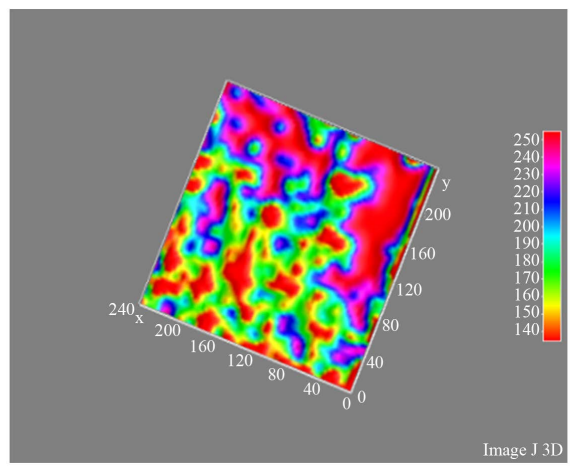

(f)

Figure 3. Processed image of $870^{\circ} \mathrm{C}$ annealed steel by image analysis (using) Image J. (a) Original image - Optical Microscope; (b) processing and threshold (blue); (c) thresholded (black and white); (d) result of particle distribution (using analysis tool in Image J); (e) Area distribution of the grains; (f) Interactive 3D surface plot.

In Figure 8, the Impact and Hardness were conducted using the ASTM E23 for notched bar impact testing, from the figure, it will be observed that the highest hardness point in the series was at $129.4 \mathrm{BHN}$ at $840^{\circ} \mathrm{C}$ the hardness decreased gradually to point $118.6 \mathrm{BHN}$ which is at $990^{\circ} \mathrm{C}$. It is worthy of note that $840^{\circ} \mathrm{C}$ also had the lowest impact value at $58.75 \mathrm{~J}$ and this value was seen to increase significantly to $66.65 \mathrm{~J}$ at $990^{\circ}$. However, it was observed that as the annealing temperature increased, the hardness decreased while the impact increased. This may be due to annealing; because annealing helps to relieve internal stress and improve ductility [16]. 


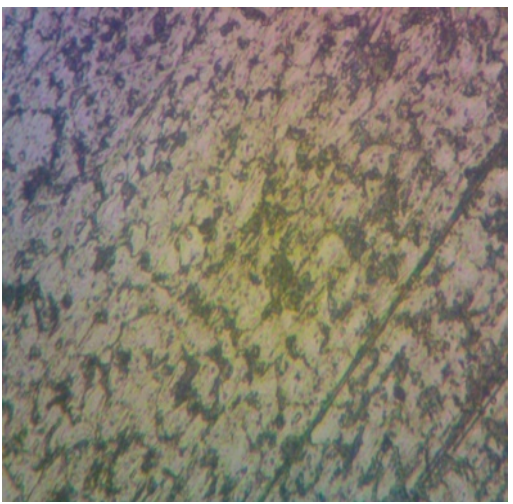

(a)

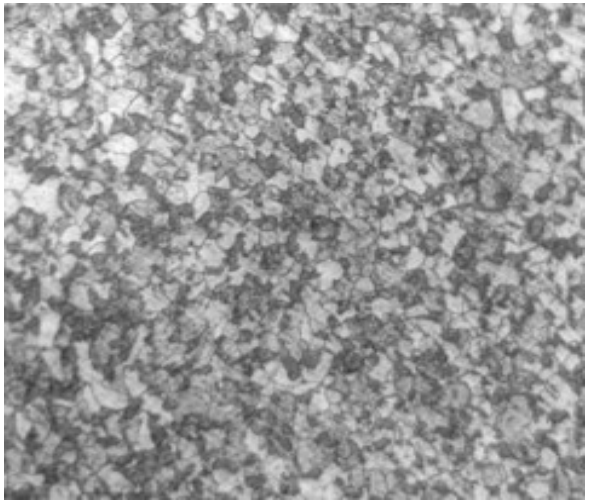

(b)

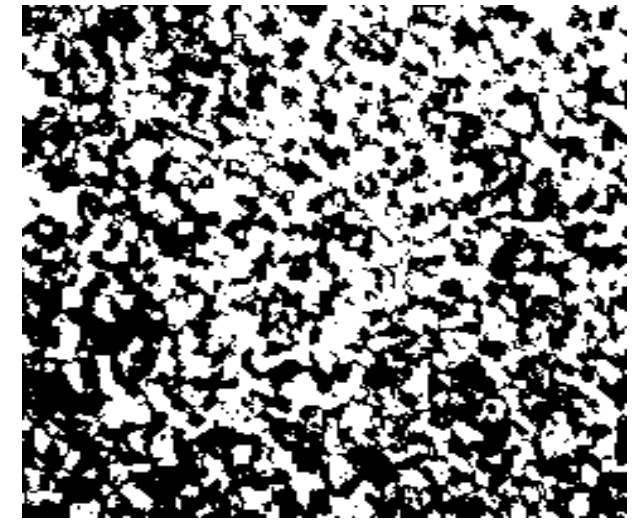

(c)

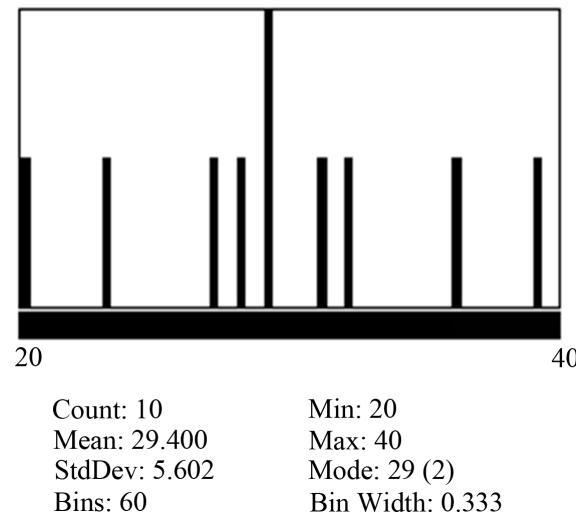

(e)

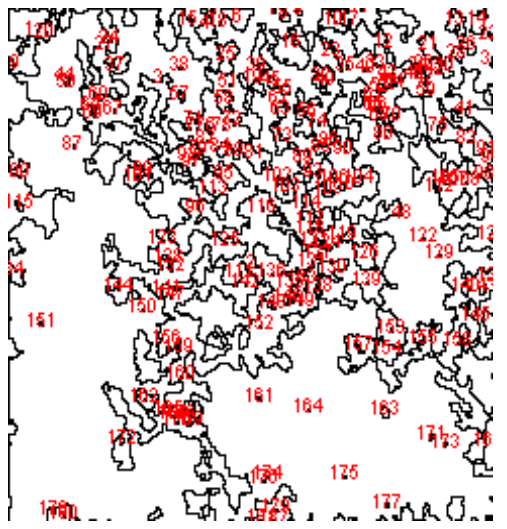

(d)

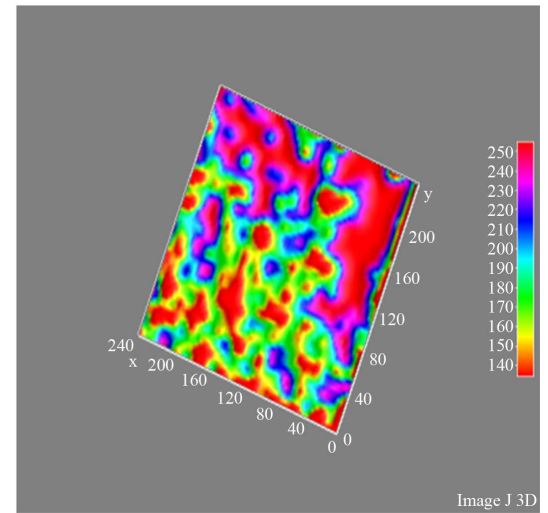

(f)

Figure 4. Processed image of $900^{\circ} \mathrm{C}$ annealed steel by image analysis (using) Image J. (a) Original image - Optical Microscope; (b) processing and threshold (blue); (c) thresholded (black and white); (d) result of particle distribution (using analysis tool in Image J); (e) Area distribution of the grains; (f) Interactive 3D surface plot.

\section{Conclusions}

In this study, we have successfully analyzed some basic parameters of $0.17 \% \mathrm{C}$ of HSLA Steels, such as the circularity, ferret angle, solidity and perimeter, average area and the percentage area using image $\mathrm{J}$.

It also showed the differences in the images of the six annealed samples. The method is automated and very reliable and accurate, very fast and can be used 


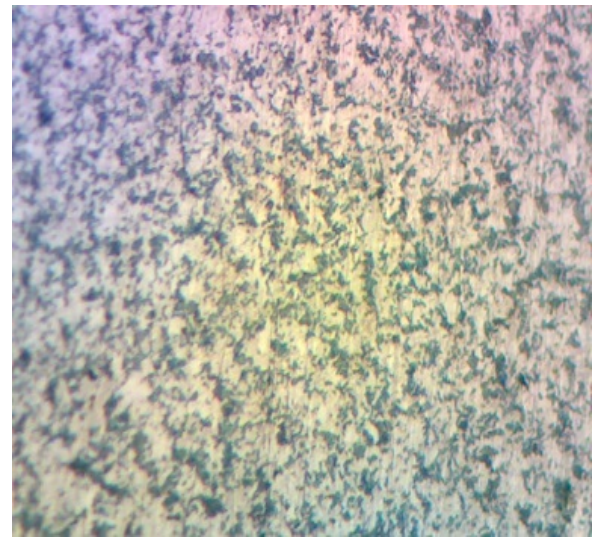

(a)

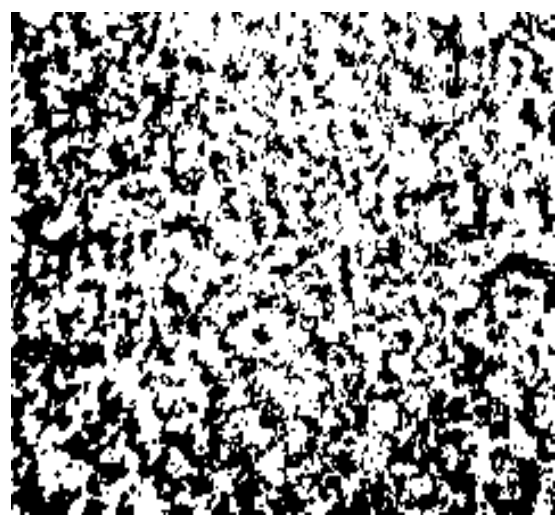

(c)

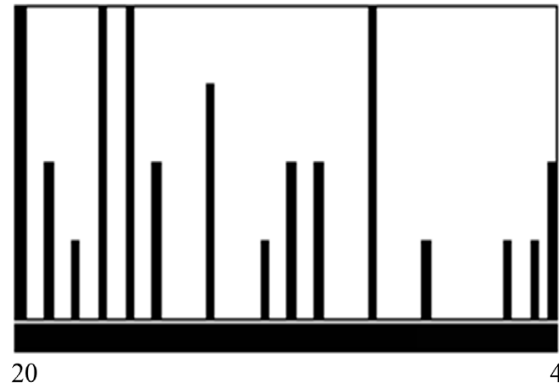

20

$\begin{array}{ll}\text { Count: } 34 & \text { Min: } 20 \\ \text { Mean: } 27.588 & \text { Max: } 40 \\ \text { StdDev: } 6.165 & \text { Mode: } 20(4) \\ \text { Bins: } 60 & \text { Bin Width: } 0.333\end{array}$

(e)

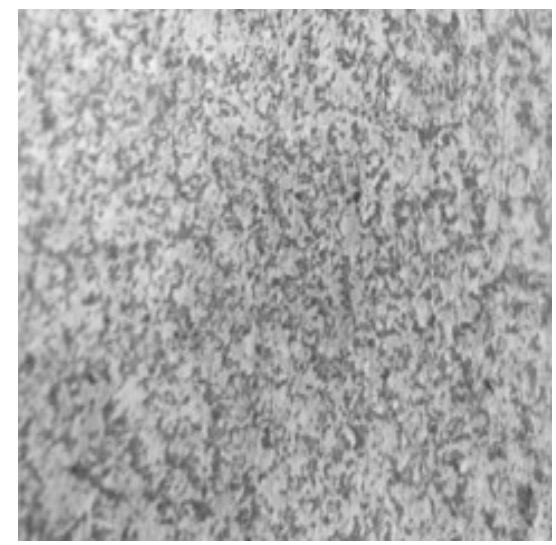

(b)

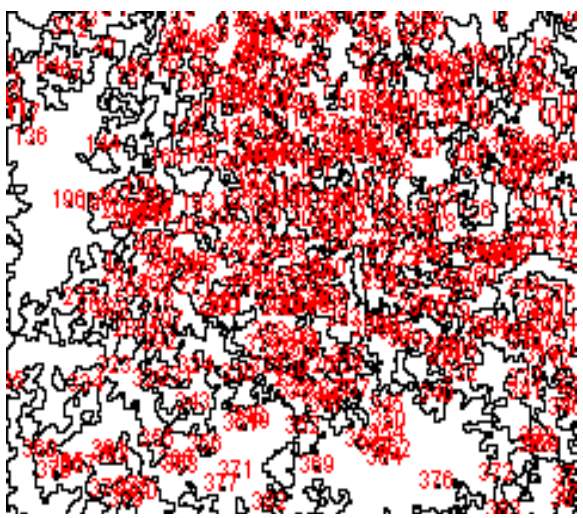

(d)

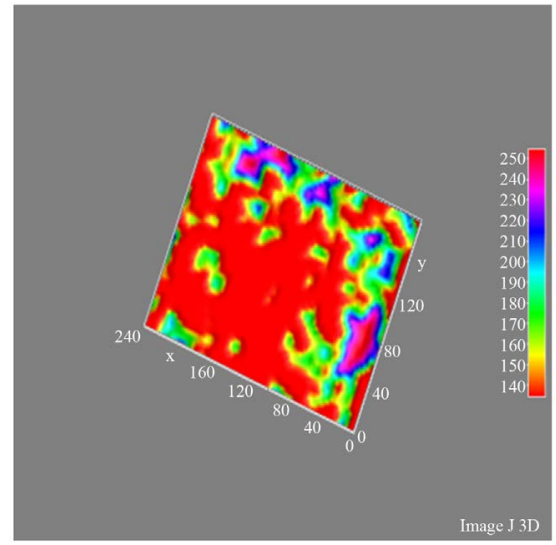

(f)

Figure 5. Processed image of $930^{\circ} \mathrm{C}$ annealed steel by image analysis (using) Image J. (a) Original image - Optical Microscope; (b) processing and threshold (blue); (c) thresholded (black and white); (d) result of particle distribution (using analysis tool in Image J); (e) Area distribution of the grains; (f) Interactive 3D surface plot.

for some sundry analysis. From the mechanical analysis result, the annealed sample at $840^{\circ} \mathrm{C}$ has a highest hardness value of $129.4 \mathrm{BHN}$ and an impact value of $58.75 \mathrm{~J}$. It was observed that at $870^{\circ} \mathrm{C}$ annealing temperature, the hardness value decreased to $125.2 \mathrm{BHN}$ while the impact value increased to $60.56 \mathrm{~J}$; $900^{\circ} \mathrm{C}$ gave a hardness value of $121.7 \mathrm{BHN}$ and impact value of $62.05 \mathrm{~J} ; 930^{\circ} \mathrm{C}$ 


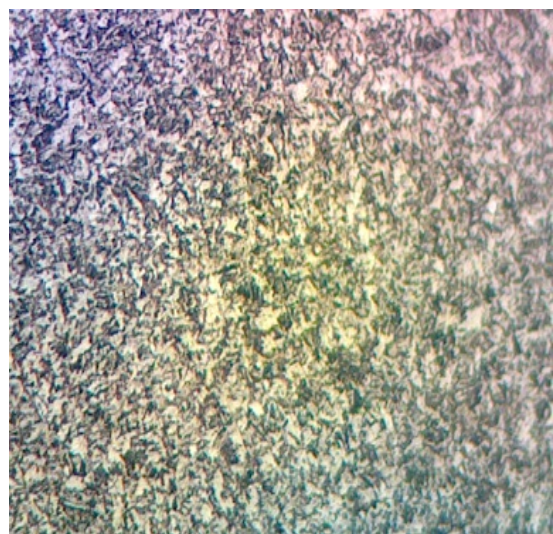

(a)

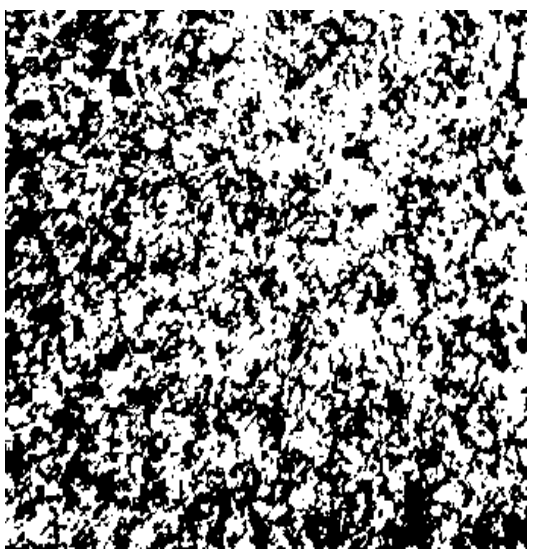

(c)

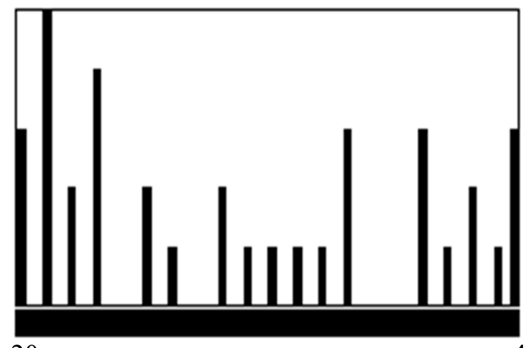

20

Count: 36

Mean: 28.722

StdDev: 7.057

Bins: 60
Min: 20

Max: 40

Mode: 21 (5)

Bin Width: 0.333

(e)

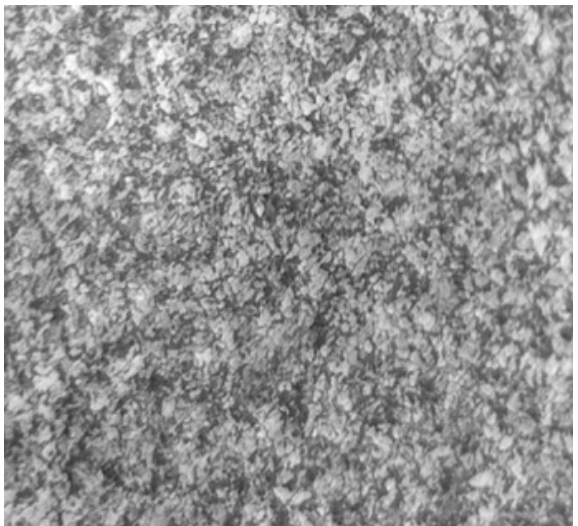

(b)

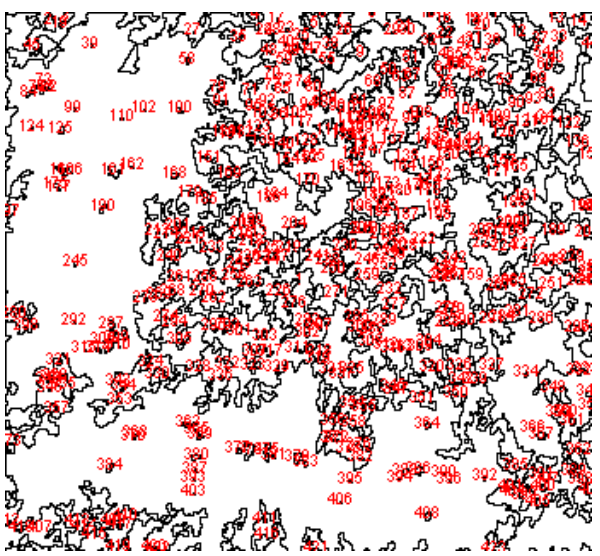

(d)

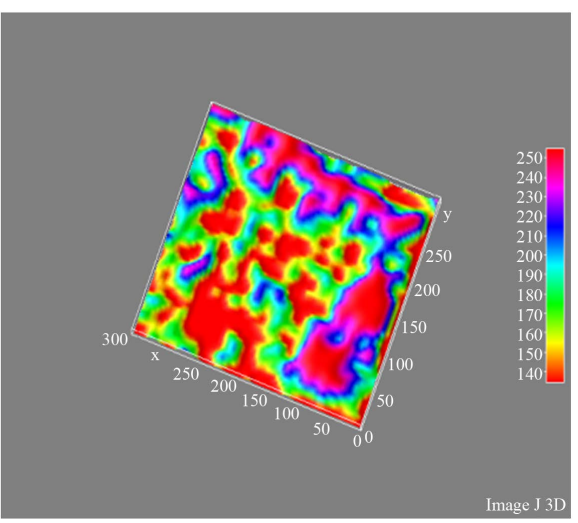

(f)

Figure 6. Processed image of $960^{\circ} \mathrm{C}$ annealed steel by image analysis (using) Image J. (a) Original image - Optical Microscope; (b) processing and threshold (blue); (c) thresholded (black and white); (d) result of particle distribution (using analysis tool in Image J); (e) Area distribution of the grains; (f) Interactive 3D surface plot.

has a hardness value of $121.7 \mathrm{BHN}$ and impact value of $63.76 \mathrm{~J}$; at $960^{\circ} \mathrm{C}$ the hardness value is $120.8 \mathrm{BHN}$ while the impact value increased to $64.80 \mathrm{~J}$. At $990^{\circ} \mathrm{C}$, we had the least value of hardness value of $118.6 \mathrm{BHN}$ and highest impact value of $66.65 \mathrm{~J}$, which means that annealing enhanced the fatigue property and tensile strength (wear strength) of the steel in study. 


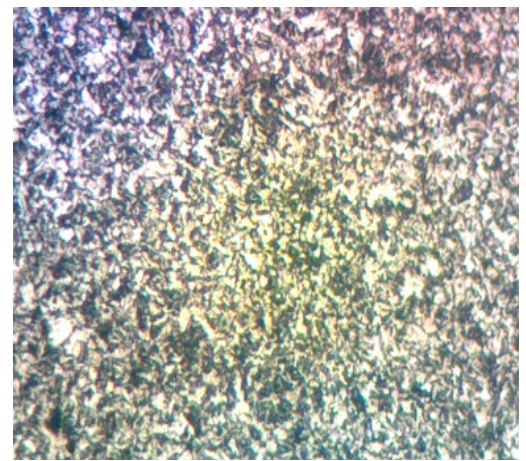

(a)

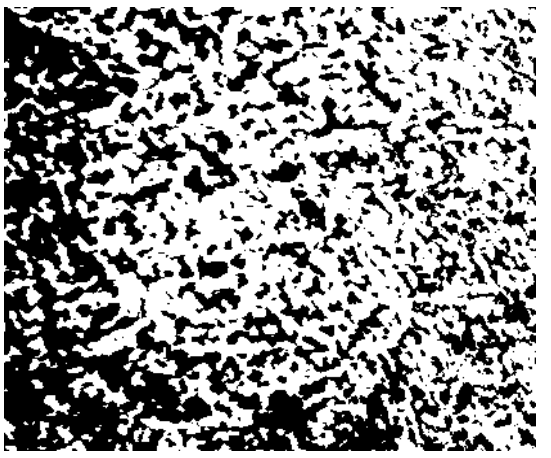

(c)

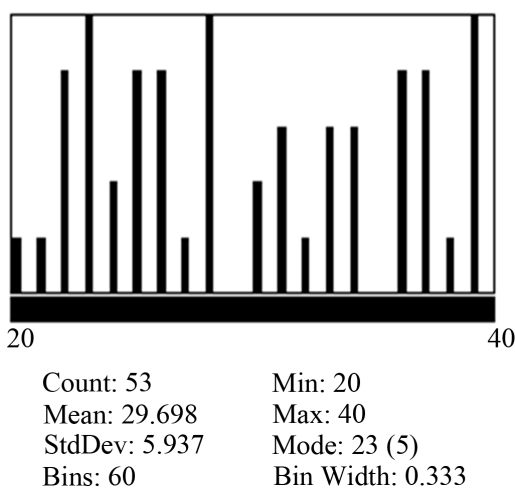

(e)

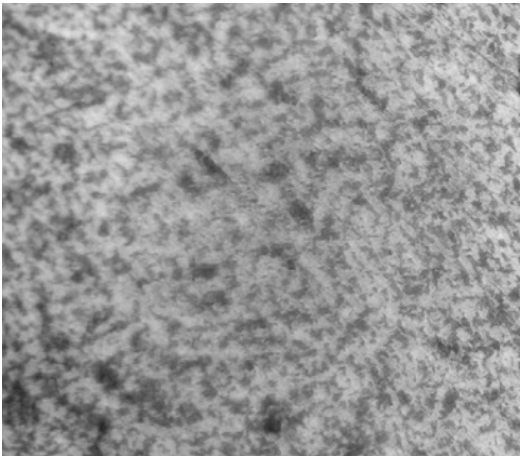

(b)

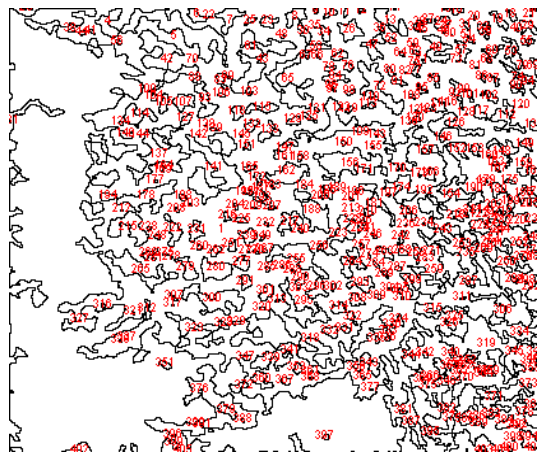

(d)

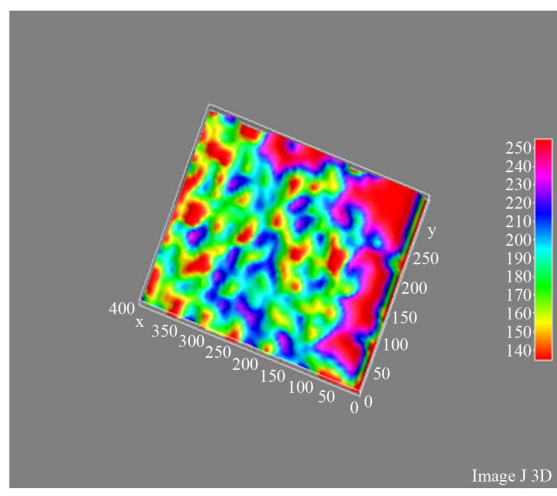

(f)

Figure 7. Processed image of $990^{\circ} \mathrm{C}$ annealed steel by image analysis (using) Image J. (a) Original image - Optical Microscope; (b) processing and threshold (blue); (c) thresholded (black and white); (d) result of particle distribution (using analysis tool in Image J); (e) Area distribution of the grains; (f) Interactive 3D surface plot.

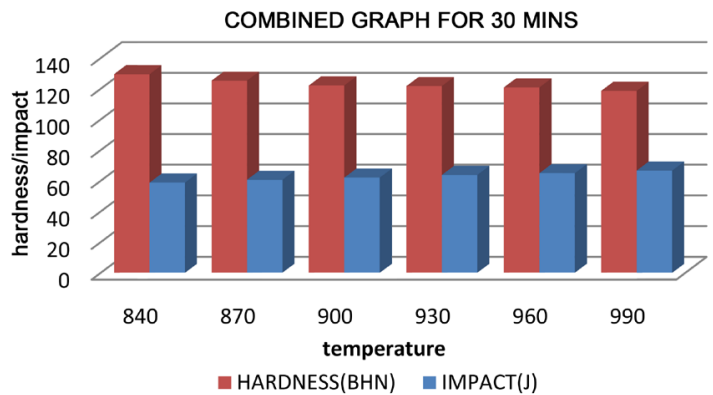

Figure 8. Impact and hardness test for 30 mins soaking time of $0.17 \%$ C HSLA steels. 


\section{Conflicts of Interest}

The authors declare no conflicts of interest regarding the publication of this paper.

\section{References}

[1] Sreeteja, M., Pranavadithya, S., Nitish, V. and Sowmya, G. (2017) Experimental Investigation on the Effect of Annealing on Fatigue Life of SAE 202 and 440C Steels. International Journal of Current Engineering and Technology, 7, 857-861.

[2] Hu, J.Z., Wang, S.M., Zhao, X.L. and Yu, B.T. (2010) Structure and Performance of Welding Structure and Performance of Welding Joint of Q235 Steel Welded by SHS Welding. Mechanical Engineering in China, 5, 189-193. https://doi.org/10.1007/s11465-010-0003-3

[3] Zhao, Z., Wu, H., Peng, C., Sun, B., Guo, B., Liang, J. and Tang, D. (2017) Mechanical Behavior of Two Materials. Proceedings of the 18 th International Congress of Mechanical Engineering, Ouro Preto, 6-11 November 2017.

[4] Policena, M.R., Trindade, A., Fripp, W.H., Israel, C.L., Fronza, G. and João de Souza, A. (2019) Fatigue Failure Analysis of HSLA Steel Sheets Holed by Conventional and Flow Drilling Processes. Revista Matéria, 24.

https://doi.org/10.1590/s1517-707620190003.0784

[5] Jia, D., Ramesh, K.T. and Ma, E. (2003) Effect of Monocrystalline and Ultrafine Grain Sizes on Constructive Behaviour and Shear Bands in Iron. Acta Materialia, 51, 3495-3509. https://doi.org/10.1016/S1359-6454(03)00169-1

[6] Vervynckts, S., Thibamx, P. and Verbeken, K. (2012) Effect of Niobium on Microstructure and Mechanical Properties of Hot Rolled Micro alloyed Steels after Recrystallization-Controlled Rolling. Metals and Materials International, 18, 37-46. https://doi.org/10.1007/s12540-012-0005-2

[7] Bhadesia, H.K.D.H and Honeycombe, R.W.K. (2006) Steel: Microstructure and Properties. 3rd Edition, Butterworth-Heinemann, Oxford.

[8] Dzupon, M., Parilak, I., Kollarova, M. and Sinaiova, I. (2006) Dual Phase Ferrite-Martensitic Steel Micro Alloyed with V-Nb. Metalurgija, 46, 15-20.

[9] Kadkhodapour, J., Butz, A. and Rad, S.Z. (2011) Mechanisms of Void Formation during Tensile Testing in a Commercial, Dual-Phase Steel. Acta Materialia, 59, 2575-2588. https://doi.org/10.1016/j.actamat.2010.12.039

[10] Arasu, T.P., Dhansekaram, R., Kumar, S.P. and Srinivasan, N. (2013) Effect of Hardness and Microstructure on En 353 Steel by Heat Treatment. International Journal of Engineering and Science, 2, 1-5.

[11] American Society for Metals (ASM) (2001) Alloying: Understanding the Basics. Ferrite-Martensite Dual-Phase Steels over a Broad Range of Strain Rates. Metals International, Materials Park, Ohio. http://www.asminternational.org/

[12] Schneider, C.A., Rasband, W.S. and Eliceiri, K.W. (2012) NIH Image to ImageJ: 25 Years of Image Analysis. Nature Methods, 9, 671-675. https://doi.org/10.1038/nmeth.2089

[13] Dang, A.T., Vo, T.T. and Le, V.P. (2014) Analyzing 2D structure Images of Piezoelectric Ceramics Using ImageJ. International Journal of Materials and Chemistry, 4 , 88-91.

[14] Miroslaw, S., Winiarski, G., Wójcik, Ł. and Bulzak, T. (2020) Effect of Annealing Time and Temperature Parameters on the Microstructure, Hardness, and Strain- 
Hardening Coefficients of $42 \mathrm{CrMo} 4$ Steel. International Journals of Microstructures and Mechanical Properties of Alloy, 13, 2022. https://doi.org/10.3390/ma13092022

[15] Senthil, S., Pradeep, S., Senthamaraikannan, P., Sanjay, M. and Mohammad Jawaid, P. (2018) Characterization and Properties of Natural Fiber Polymer Composites: A Comprehensive Review. Journal of Cleaner Production, 172, 566-581. https://doi.org/10.1016/j.jclepro.2017.10.101

[16] Al-Qawabah, S.M.A., Nabeel Alshabatat, U.F. and Al-Qawabeha, G. (2012) Effect of Annealing Temperature on the Microstructure, Microhardness, Mechanical Behavior and Impact Toughness of Low Carbon Steel Grade 45. International Journal of Engineering Research and Applications (IJERA), 2, 1550-1553. 